\title{
Dilation of Epicardial Coronary Arteries by the G Protein-Coupled Estrogen Receptor Agonists G-1 and ICI 182,780
}

\author{
Matthias R. Meyer ${ }^{\mathrm{a}, \mathrm{b}}$ Oliver Baretella ${ }^{\mathrm{a}}$ Eric R. Prossnitz ${ }^{\mathrm{c}}$ Matthias Barton ${ }^{\mathrm{a}}$ \\ a Molecular Internal Medicine, University of Zurich, and bepartment of Internal Medicine, Triemli City Hospital, \\ Zurich, Switzerland; ' Department of Cell Biology and Physiology and University of New Mexico Cancer Center, \\ University of New Mexico Health Sciences Center, Albuquerque, N. Mex., USA
}

\section{Key Words}

Atherosclerosis - Coronary artery disease - Estrogen •

Faslodex $\cdot$ Fulvestrant $\cdot$ Myocardial infarction $\cdot$ Vasodilation

\begin{abstract}
Endogenous estrogens protect from coronary artery disease in premenopausal women, but the mechanisms involved are only partly understood. This study investigated whether activation of the novel $G$ protein-coupled estrogen receptor (GPER, formerly known as GPR30) affects coronary artery tone, and whether this is affected by concomitant blockade of estrogen receptors (ER) $\alpha$ and $\beta$. Rings of epicardial porcine coronary arteries suspended in organ chambers were precontracted with prostaglandin $F_{2} \alpha$, and direct effects of G-1 (GPER agonist) and ICI 182,780 (GPER agonist and ER $\alpha$ / ER $\beta$ antagonist) were determined. In addition, indirect effects on contractility to endothelin-1 and serotonin (a vasoconstrictor released from aggregating platelets during acute myocardial infarction) were assessed. ICI 182,780 and G-1 caused acute dilation of coronary arteries to a comparable degree ( $p<0.05$ vs. solvent control). Both GPER agonists attenuated contractions to endothelin-1 ( $p<0.05$ vs. ethanol), but not to serotonin (n.s.). In summary, these findings provide evidence for direct and indirect coronary artery dilator effects of GPER independent of ER $\alpha$ and ER $\beta$, and are the first demonstration of arterial vasodilation in response to ICI 182,780.

Copyright $\odot 2010$ S. Karger AG, Basel
\end{abstract}

\section{Introduction}

Coronary artery disease, which predominantly affects epicardial coronary arteries [1], represents the leading cause of death worldwide in women and men alike [2]. Endogenous estrogens protect from development of coronary atherosclerosis in premenopausal women [3] and are involved in the regulation of vascular tone and, thus, blood pressure [4]. These effects have mainly been attributed to activation of estrogen receptors (ER) $\alpha$ and $\beta$ [3]. Natural estrogen (17 $\beta$-estradiol) acutely dilates human and porcine coronary arteries $[5,6]$, and also inhibits responses to vasoconstrictors [6-9]. Using selective agonists for either ER $\alpha$ or ER $\beta$, individual roles of these receptors mediating dilation of coronary arteries have been demonstrated [6].

The transmembrane $G$ protein-coupled estrogen receptor (GPER, formerly known as GPR30) is a novel intracellular ER and localizes to the endoplasmic reticulum [10-12]. GPER is highly expressed in human arteries [13], and recent studies have demonstrated that the selective GPER agonist G-1 [14] acutely dilates extracardial arteries of humans and rodents, an effect absent in animals lacking the GPER gene [15-17]. In line with its vasodilator effects, infusion of G-1 causes a marked reduction in blood pressure [15].

The ER modulator ICI 182,780 has originally been considered a 'pure' anti-estrogen with high affinity for

\section{KARGER}

(C) 2010 S. Karger AG, Basel

Fax +41613061234

E-Mail karger@karger.ch

www.karger.com
Accessible online at:

www.karger.com/pha
Matthias Barton, MD

Molecular Internal Medicine, University of Zurich

LTK Y44 G22, Winterthurerstrasse 190

CH-8057 Zurich (Switzerland)

Tel. +41 7743955 54, Fax +41 4463568 75, E-Mail barton@access.uzh.ch 
$\mathrm{ER} \alpha$ and ER $\beta$, which completely blocks ER action [18, 19]. These characteristics prompted its use as an ER $\alpha /$ ER $\beta$ antagonist in experimental studies and as drug treatment for advanced breast cancer $[19,20]$. More recent data, however, indicate that ICI 182,780 also acts as an estrogen agonist by binding to GPER and activating rapid intracellular signaling $[10,12]$. Whether GPER activation by ICI 182,780 has effects on vascular tone is unknown.

We $[6,21]$ and others $[8,9,22,23]$ have previously used porcine coronary arteries as a model of human coronary arteries because of high anatomic and physiological similarities [24]. The present study, using G-1 and ICI 182,780 as GPER agonists, was set out to investigate whether GPER activation directly or indirectly regulates epicardial coronary artery tone, and to determine whether effects are affected by concomitant blockade of ER $\alpha$ and ER $\beta$.

\section{Methods}

\section{Preparation of Coronary Arteries}

Porcine hearts were obtained at the local abattoir and immediately immersed in cold $\left(4^{\circ} \mathrm{C}\right)$ physiological Krebs-Ringer bicarbonate solution (composition in mmol/l: $118.6 \mathrm{NaCl}, 4.7 \mathrm{KCl}, 2.5$ $\mathrm{CaCl}_{2}, 1.2 \mathrm{MgSO}_{4}, 25.1 \mathrm{NaHCO}_{3}, 1.2 \mathrm{KH}_{2} \mathrm{PO}_{4}, 0.026 \mathrm{EDTA}_{\mathrm{Na} 2 \mathrm{Ca}}$ 10.1 glucose). Epicardial left anterior descending arteries were dissected free from surrounding myocardium, carefully cleaned from adherent connective tissue and fat, and cut into rings 4$5 \mathrm{~mm}$ in length. In a subset of rings, the endothelium was removed by gently rubbing the intimal surface with a soft wooden probe. Experiments were conducted according to the institutional guidelines and the Guide for the Care and Use of Laboratory Animals published by the U.S. National Institutes of Health.

\section{Vascular Function Experiments}

Isolated coronary artery rings were suspended in organ chambers containing Krebs-Ringer bicarbonate solution $\left(37^{\circ} \mathrm{C}\right.$, $\mathrm{pH} 7.4$, oxygenated with $95 \% \mathrm{O}_{2}$ and $5 \% \mathrm{CO}_{2}$ ), and connected to force transducers as described [5]. Rings were progressively stretched and repeatedly exposed to $\mathrm{KCl}(100 \mathrm{mmol} / \mathrm{l})$ until the optimal tension for generating force during isometric contraction was reached. All rings were preincubated with the cyclooxygenaseinhibitor meclofenamate $(1 \mu \mathrm{mol} / \mathrm{l})$ for $30 \mathrm{~min}$ to rule out any effects of cyclooxygenase-dependent vasoconstrictors. Selected rings were also incubated with L-NAME (300 $\mu \mathrm{mol} / \mathrm{l})$ for $30 \mathrm{~min}$ to inhibit nitric oxide (NO) synthesis. Endothelium removal was confirmed by the complete lack of a relaxant response to bradykinin $(1 \mu \mathrm{mol} / \mathrm{l}$, data not shown). Coronary artery rings were precontracted with prostaglandin $\mathrm{F}_{2 \alpha}$ to approximately $30 \%$ of contraction to $\mathrm{KCl}$, and exposed to the selective GPER agonist G-1 [14] or the GPER agonist and ER $\alpha / E R \beta$ antagonist ICI 182,780 $[10,12,18,19]$. A single concentration of $3 \mu \mathrm{mol} / 1$ was chosen based on previous studies [15-17]. Changes in vascular tone were recorded for $60 \mathrm{~min}$. Ethanol at a final concentration of $0.3 \%$ (vol/ vol) served as solvent control. In addition, concentration-response curves to endothelin-1 $(0.1 \mathrm{nmol} / 1-0.1 \mu \mathrm{mol} / \mathrm{l})$ and serotonin (10 $\mathrm{nmol} / \mathrm{l}-30 \mu \mathrm{mol} / \mathrm{l})$ were obtained following preincubation with G-1 $(3 \mu \mathrm{mol} / \mathrm{l})$, ICI $182,780(3 \mu \mathrm{mol} / \mathrm{l})$ or ethanol $(0.3 \% \mathrm{vol} / \mathrm{vol})$ for $30 \mathrm{~min}$ as described for $17 \beta$-estradiol [7].

\section{Drugs}

Meclofenamate, serotonin, bradykinin and sodium nitroprusside were from Sigma-Aldrich (St. Louis, Mo., USA). L-NAME $\left(\mathrm{N}^{\omega}\right.$-nitro-L-arginine methyl ester) and endothelin-1 were from Alexis Biochemicals (Framingdale, N.Y., USA). Prostaglandin $F_{2 \alpha}$ was from Cayman Chemicals (Ann Arbor, Mich., USA), ICI $182,780 \quad(7 \alpha, 17 \beta$-[9-(4,4,5,5,5-pentafluoropentylsulfinyl)nonyl] estra-1,3,5(10)-triene-3,17-diol) from Tocris Bioscience (Ellisville, Mo., USA), and G-1 (1-(4-(6-bromobenzo[1,3]dioxol-5-yl)$3 \alpha, 4,5,9 \beta$-tetrahydro-3H-cyclopenta[c] quinolin-8-yl)-ethanone) from Calbiochem (Darmstadt, Germany). ICI 182,780 and G-1 were dissolved in $99 \%$ ethanol. All other substances were dissolved in water. Stock solutions were diluted in Krebs-Ringer bicarbonate solution to the required concentration before use. Concentrations are expressed as final molar concentration in the organ chamber.

\section{Calculations and Statistical Analyses}

Data are expressed as means \pm SEM. Relaxation is expressed as the percentage of precontraction, and contraction is given as the percentage of contraction to $\mathrm{KCl}(100 \mathrm{mmol} / \mathrm{l})$. $\mathrm{EC}_{50}$ values (as negative logarithm: $\mathrm{pD}_{2}$ ), area under the curve (AUC), and maximal responses $\left(\mathrm{E}_{\max }\right)$ were calculated by non-linear regression analysis [25]. ANOVA for repeated measurements, the MannWhitney $U$ test, or the unpaired Student's $t$ test were used when appropriate. Statistical significance was accepted at $\mathrm{p}<0.05$.

\section{Results}

\section{Dilation of Coronary Arteries in Response to G-1 and ICI 182,780}

The selective GPER agonist G-1 [14] induced dilation of precontracted epicardial coronary arteries $(38 \pm 5 \%$ at $60 \mathrm{~min}, \mathrm{p}=0.005$ vs. ethanol; fig. 1a). Similar vasodilator responses were seen using ICI 182,780 as a GPER agonist $[10,12]$, which simultaneously blocks $\mathrm{ER} \alpha$ and $\mathrm{ER} \beta$ (41 $\pm 7 \%$ at $60 \mathrm{~min}, \mathrm{p}=0.01$ vs. ethanol; fig. $1 \mathrm{~b})[18,19]$. The dilator response induced by G-1 was completely abolished by the NO synthase inhibitor L-NAME $(16 \pm 2 \%$ vs. $16 \pm 4 \%$ at $60 \mathrm{~min}$, n.s.; fig. 1c) or in rings without endothelium (19 $\pm 2 \%$ vs. $16 \pm 4 \%$ at $60 \mathrm{~min}$, n.s.; fig. $1 \mathrm{~d}$ ). Precontraction with prostaglandin $\mathrm{F}_{2 \alpha}$ and maximal contraction to $\mathrm{KCl}$ of coronary artery rings did not differ between groups (data not shown).

\section{GPER Activation Inhibits Endothelin-1- but Not \\ Serotonin-Induced Vasoconstriction}

Endothelin-1 caused potent and concentration-dependent coronary contractions (fig. 2a, b). Pretreatment with either G-1 or ICI 182,780 considerably, and to a com- 
Fig. 1. Vasodilator responses to GPER agonists in epicardial coronary arteries. a Direct vasodilator responses to the GPER agonist ICI $182,780(\boldsymbol{\Delta}, \mathrm{n}=6)$, which also blocks ER $\alpha$ and ER $\beta$. b Direct vasodilator responses to the selective GPER agonist G-1 in endothelium-intact arteries $(\bullet, n=$ 6). c G-1-induced vasodilation in endothelium-intact arteries the absence $(\bullet)$ or presence $(\square)$ of the NO synthase inhibitor L-NAME $(n=6)$. d G-1-dependent vasodilation in intact $(\bullet)$ and endothelium-denuded arteries $(\diamond, \mathrm{n}=8) .{ }^{*} \mathrm{p}<0.05$ versus solvent control (EtOH, 0.3\% ethanol, $\mathrm{n}=$ $7) ;{ }^{\dagger} \mathrm{p}<0.05$ versus $\mathrm{G}-1$.
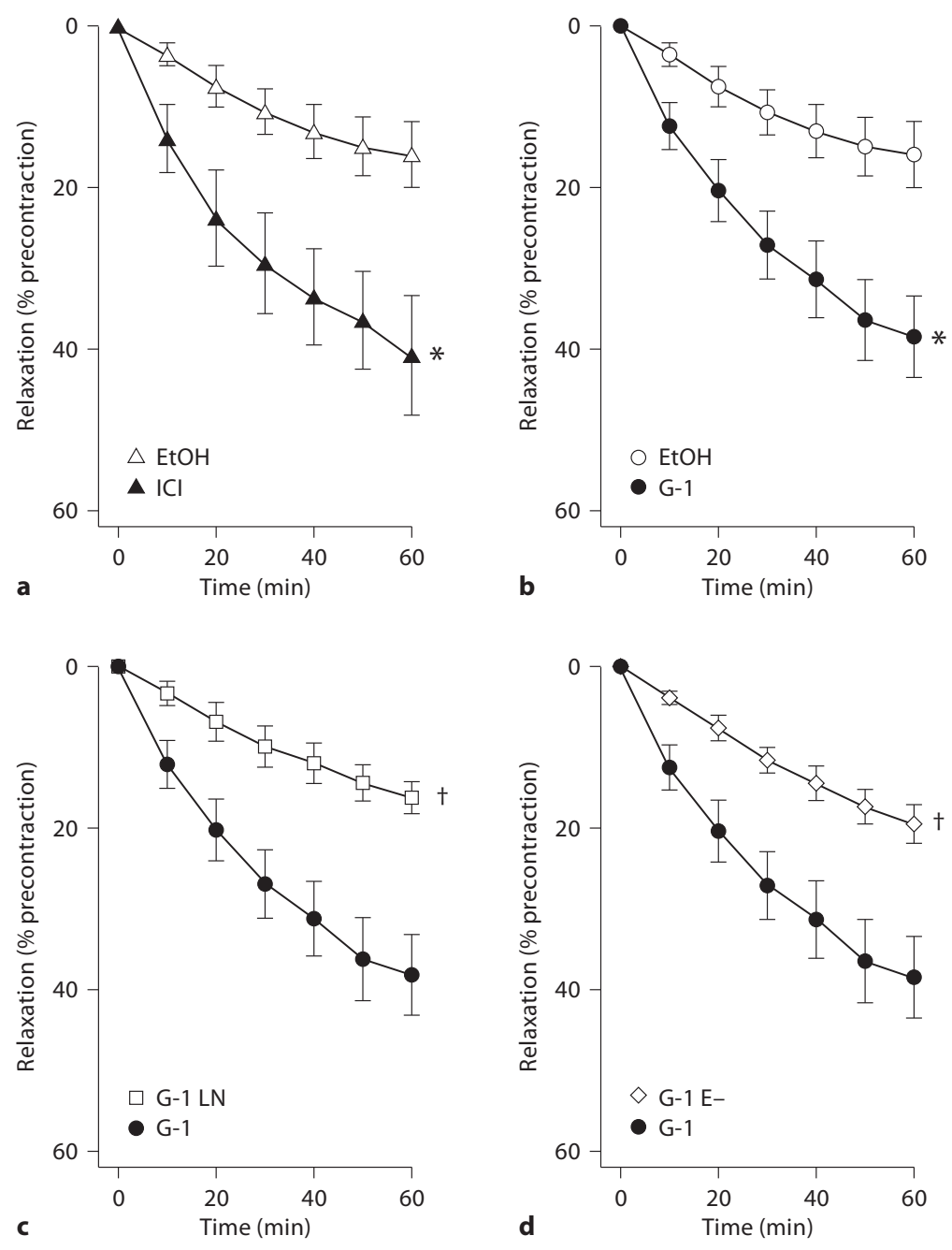

parable degree, attenuated the response to endothelin-1 at $30 \mathrm{nmol} / 1$ concentration ( -23 and $-25 \%$, respectively, $\mathrm{p}<0.05$ vs. ethanol; fig. $2 \mathrm{a}, \mathrm{b})$, whereas this effect was less pronounced at $100 \mathrm{nmol} / \mathrm{l}$ concentration $(-10$ or $-13 \%$, respectively, $\mathrm{p}<0.05$ vs. ethanol; fig. $2 \mathrm{a}, \mathrm{b}$ ). Compared with endothelin-1, serotonin caused only weak contractions about one seventh in magnitude compared with endothelin-1 (fig. 2c, d). Neither G-1 nor ICI 182,780 had any effect on contractions to serotonin (fig. $2 \mathrm{c}, \mathrm{d}$ ), and no difference was observed between groups with regard to $\mathrm{pD}_{2}$ values (ethanol: $6.32 \pm 0.02 \mu \mathrm{mol} / \mathrm{l}$; G-1: $6.27 \pm 0.04$ $\mu \mathrm{mol} / \mathrm{l}$; ICI 182,780: $6.17 \pm 0.11 \mu \mathrm{mol} / \mathrm{l})$, AUC (ethanol: $21.6 \pm 2.3$ AU; G-1: $30.5 \pm 4.3$ AU; ICI 182,780: $19.7 \pm$ 2.0 AU), and $\mathrm{E}_{\max }$ (ethanol: $11.8 \pm 1.2 \%$; G-1: $17.0 \pm$ 2.4\%; ICI 182,780: $11.7 \pm 1.0 \%$ ).

\section{Discussion}

This study demonstrates that activation of GPER directly and indirectly causes dilation of epicardial porcine coronary arteries. The GPER activating compound ICI $182,780[10,12]$, which concomitantly blocks ER $\alpha$ and ER $\beta[18,19]$, has similar coronary dilator effects as G-1, which activates only GPER [14]. Contractions to endothelin-1 are inhibited similarly by ICI 182,780 or G-1, whereas contractions to serotonin are weak and unaffected by GPER agonists. These findings demonstrate coronary vasodilator effects of ICI 182,780 and support a role for GPER in the regulation of coronary artery tone independent of $E R \alpha$ and $E R \beta$. 
Fig. 2. Effects of selective GPER activation by G-1 (left panels) and GPER activation with concomitant blockade of $\mathrm{ER} \alpha$ and ER $\beta$ by ICI 182,780 (right panels) in epicardial coronary arteries. a Effects of G-1 $(\bullet, \mathrm{n}=8)$ on contractions to endothelin-1 (ET-1). b Effects of ICI $182,780(\boldsymbol{\Delta}, \mathrm{n}=5)$ on contractions to endothelin-1 (ET-1). c Effects of G-1 $(\bullet, n=10)$ on contractions to serotonin (5-hydroxytryptamine, 5-HT). d Effects of ICI 182,780 ( $\boldsymbol{\Delta}, \mathrm{n}=5)$ on contractions to serotonin (5-HT). All data are means \pm SEM. ${ }^{*} \mathrm{p}<0.05$ versus solvent control (EtOH, 0.3\% ethanol, $\mathrm{n}=$ $8-11)$.
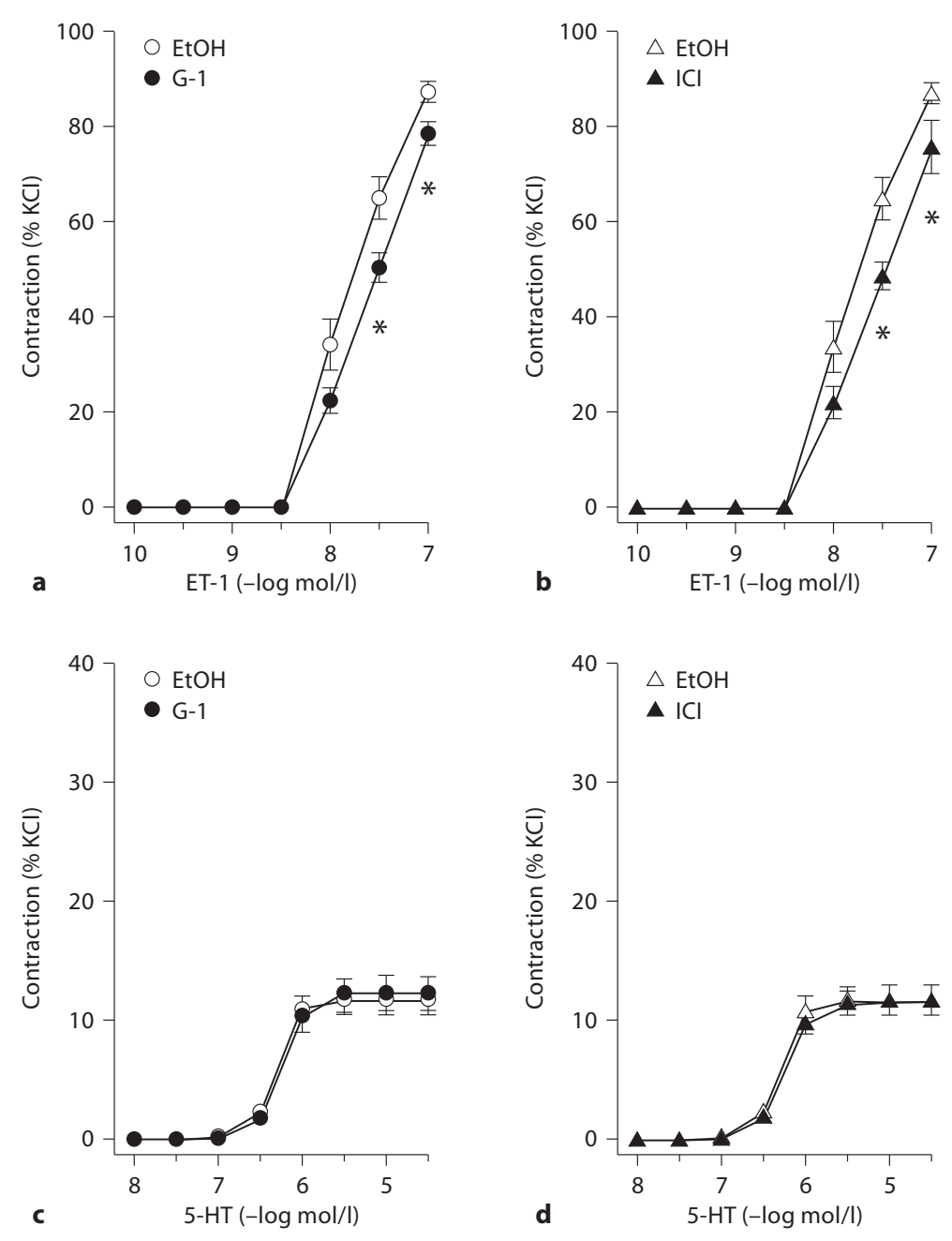

Recently, GPER has been identified as a novel transmembrane $G$ protein-coupled receptor localized to the endoplasmic reticulum that mediates rapid estrogen signaling [10-12]. The GPER gene was originally cloned from human endothelial cells [26] and is expressed in human arteries [13]. Combined activation of GPER, ER $\alpha$ and $E R \beta$ by $17 \beta$-estradiol has been shown to affect endothelium-independent and endothelium-dependent vascular tone in human and porcine epicardial coronary arteries $[5,6]$. In addition, $17 \beta$-estradiol inhibits the vasoconstrictor response to agonists such as serotonin $[7,9]$ or endothelin-1 [8, 9]. Moreover, activation of GPER by G-1 acutely dilates rodent and human arteries and lowers blood pressure [15-17].

Coronary Vasodilation by G-1 and ICI 182,780 via GPER
The effect of GPER activation in the coronary circulation has not been previously investigated. Porcine coronary arteries represent a good model of the human coronary vasculature with regard to size and function [24]. Moreover, the development of atherosclerosis can be observed also in this species under certain conditions [21, 24]. In the present study, we present evidence that activation of GPER using two different agonists is equally effective in causing rapid dilation of epicardial porcine coronary arteries and that dilator effects are independent of whether ER $\alpha$ and ER $\beta$ are concomitantly blocked or not. This indicates that the vasodilator response mediated by GPER may not depend on the activity of the other two ERs, which also mediate rapid cell signaling [3].

Pharmacology 2010;86:58-64 
ICI 182,780 was originally designed as a 'pure' antiestrogen blocking estrogen action via $\mathrm{ER} \alpha$ and $\mathrm{ER} \beta[18$, 19]; however, more recent data indicate that this compound also binds to GPER, thereby activating rapid intracellular signaling $[10,12]$. In addition, ICI 182,780 treatment of rat cardiac myocytes and fibroblasts potently inhibits cell growth [27], and estrogen-dependent inhibition of cardiomyocyte contraction involves mechanisms independent of ER $\alpha$ and ER $\beta$ [28]. The present study now demonstrates for the first time that ICI 182,780 also exerts direct coronary vasodilator effects. Interestingly, symptomatic hypotension via yet unknown mechanisms is a common side effect of ICI 182,780 (fulvestrant, Faslodex ${ }^{\circledR}$ ) when used as endocrine treatment for advanced breast cancer in women [20]. The vasodilator effects described in the present study can explain such hypotensive effects of ICI 182,780 acting through GPER. Indeed, blood pressure-lowering effects of GPER activation have been previously reported $[15,16]$. The present findings also suggest that the results of many previous studies using ICI 182,780 as a 'pure' ER $\alpha / E R \beta$ antagonist have to be reconciled.

It has previously been demonstrated that neither the vasodilator response to $17 \beta$-estradiol in porcine coronary arteries, nor estrogen-induced increases in coronary diameter or blood flow in dogs are affected by ICI 182,780 $[29,30]$. Moreover, and in line with these findings and the present study, no effect of ICI 182,780 on $17 \beta$-estradiolinduced relaxations has been found in other vascular beds of different species [31-33], indirectly suggesting vasodilator effects via GPER as shown here. In contrast, ICI 182,780 only in part attenuates estrogen-induced vasodilation in the rat aorta [34]. These conflicting results are likely due to anatomical or species differences.

Several laboratories, including ours, have shown that selective activation of ER $\alpha$ is associated with endothelium- and NO-dependent vasodilation $[6,35,36]$, whereas selective activation of ER $\beta$ induces dilation via endothelium-dependent hyperpolarization $[6,37]$. Unlike the rapid $\mathrm{ER} \alpha$-mediated response, which involves $\mathrm{NO}$ and occurs in the first minute [6], the dilator response mediated by GPER is somewhat slower in onset. However, the magnitude and the time course of the vasodilator response to G-1 in epicardial porcine coronary arteries are comparable to those seen in human internal mammary and murine arteries [15]. The present study confirms that acute vasodilation mediated by G-1 is endothelium- and $\mathrm{NO}$-dependent $[16,17]$, and extends these previous findings for the coronary circulation, in which - in contrast to the rat aorta - both NO and endothelium-dependent hyperpolarization play a role $[7,37]$. The present findings are also in line with studies using the selective ER modulator tamoxifen, another GPER agonist [11], reporting acute vasodilation of rabbit and porcine coronary arteries through endothelium- and NO-dependent mechanisms $[22,38]$.

The present study is the first demonstrating that activation of GPER attenuates endothelin-1-induced coronary vasoconstriction. Accordingly, the nonselective ER agonist $17 \beta$-estradiol reduces the constrictive response to endothelin-1 in porcine coronary arteries in vitro and in vivo $[8,9]$. This inhibitory effect was absent if animals were older [23], suggesting that the vascular response to sex steroids in coronary arteries may change with age. A similar hypothesis has been put forward by Miller et al. [39], who found that certain vasoprotective effects of estrogens are lost in aging arteries.

Serotonin is a vasoconstrictor released from aggregating platelets during acute myocardial infarction [24]. $17 \beta$-estradiol inhibits serotonin-induced contractions in mammary and coronary arteries from humans and pigs in vitro $[7,9]$. In contrast, serotonin caused only small decreases in porcine coronary diameter in vivo, which were unaffected by estrogen administration [8]. The role of selective GPER activation for serotonin-induced coronary vasoconstriction has not been previously studied. In the present study, GPER activation did not affect serotonin-induced vasoconstriction. Interestingly, contractions to serotonin were much weaker compared to endothelin-1. We have previously reported that in human internal mammary arteries and in mouse carotid arteries, activation of GPER inhibits serotonin-mediated contractions [15]. The present study confirms that serotonin is a weak constrictor of epicardial porcine coronary arteries compared with endothelin-1 [9], and it is possible that regional anatomical differences or species differences also play a role in the observed lack of effect of the GPER agonists.

In the present study, we have identified the GPER agonist ICI 182,780 as a novel coronary vasodilator with similar efficacy as the selective GPER agonist G-1. Our findings therefore suggest that GPER activation acutely reduces coronary tone via direct and indirect mechanisms irrespective of whether ER $\alpha$ and ER $\beta$ are blocked or not. Consistent with dilator effects, GPER activation reduces blood pressure in animals $[15,16]$ and improves functional recovery and infarct size after myocardial ischemia $[40,41]$.

These present results also suggest that GPER may contribute to the beneficial coronary and vascular effects of 
estrogens in premenopausal women [3]. In line with this notion and the potential clinical relevance for treating patients at risk for coronary atherosclerosis and myocardial infarction, it has been recently reported that treatment with the selective ER modulator raloxifene, which also acts as a GPER agonist (unpublished observation), or lasofoxifene reduces cardiovascular events in younger postmenopausal women $[42,43]$. The exact role of GPER for cardiovascular health and disease and its functional or molecular interactions with the L-arginine NO-pathway described in the present and in other reports [44] still needs to be clarified further in future studies.

Taken together, this study provides evidence for direct and indirect coronary vasodilator effects of agonists of GPER and for the first time shows coronary vasodilation in response to the GPER agonist ICI 182,780. The present findings also show that GPER-mediated effects require endothelium-derived $\mathrm{NO}$, and that the dilator effects through GPER are not affected by concomitant blockade of ER $\alpha$ and ER $\beta$. The present findings may be of importance for understanding the clinical effects and side effects of ICI 182,780 (fulvestrant, Faslodex) and suggest therapeutic potential of GPER agonists for the treatment of cardiovascular disease and arterial hypertension.

\section{Acknowledgements}

We thank Clemens Bauer, DVM, Head of Veterinary Services, Stadt Zürich, Umwelt und Gesundheitsschutz, for his invaluable support and for providing us with the porcine hearts. This study was supported by the Swiss National Science Foundation (SNF) grants No. 3200-108258/1 and No. K-33KO-122504/1 (to M.B.) and NIH grants and CA-116662 and CA-118743 (to E.R.P.).

\section{References}

1 Fox B, James K, Morgan B, Seed A: Distribution of fatty and fibrous plaques in young human coronary arteries. Atherosclerosis 1982; 41:337-347.

2 Yusuf S, Reddy S, Ounpuu S, Anand S: Global burden of cardiovascular diseases: part I: general considerations, the epidemiologic transition, risk factors, and impact of urbanization. Circulation 2001;104:2746-2753.

3 Meyer MR, Haas E, Barton M: Gender differences of cardiovascular disease: new perspectives for estrogen receptor signaling. Hypertension 2006;47:1019-1026.

4 White RE: Estrogen and vascular function. Vascul Pharmacol 2002;38:73-80.

5 Mügge A, Riedel M, Barton M, Kuhn M, Lichtlen PR: Endothelium independent relaxation of human coronary arteries by 17 beta-oestradiol in vitro. Cardiovasc Res 1993;27:1939-1942.

-6 Traupe T, Stettler CD, Li H, Haas E, Bhattacharya I, Minotti R, Barton M: Distinct roles of estrogen receptors alpha and beta mediating acute vasodilation of epicardial coronary arteries. Hypertension 2007;49: 1364-1370.

7 Mügge A, Barton M, Fieguth HG, Riedel M: Contractile responses to histamine, serotonin, and angiotensin II are impaired by 17 beta-estradiol in human internal mammary arteries in vitro. Pharmacology 1997;54:162168.

-8 Sudhir K, Ko E, Zellner C, Wong HE, Hutchison SJ, Chou TM, Chatterjee K: Physiological concentrations of estradiol attenuate endothelin 1-induced coronary vasoconstriction in vivo. Circulation 1997;96:3626-3632.
9 Teoh H, Quan A, Leung SW, Man RY: Differential effects of 17beta-estradiol and testosterone on the contractile responses of porcine coronary arteries. Br J Pharmacol 2000;129:1301-1308.

10 Filardo EJ, Quinn JA, Bland KI, Frackelton AR Jr: Estrogen-induced activation of Erk-1 and Erk-2 requires the G protein-coupled receptor homolog, GPR30, and occurs via trans-activation of the epidermal growth factor receptor through release of HB-EGF. Mol Endocrinol 2000;14:1649-1660.

- 11 Revankar CM, Cimino DF, Sklar LA, Arterburn JB, Prossnitz ER: A transmembrane intracellular estrogen receptor mediates rapid cell signaling. Science 2005;307:16251630.

12 Thomas P, Pang Y, Filardo EJ, Dong J: Identity of an estrogen membrane receptor coupled to a $G$ protein in human breast cancer cells. Endocrinology 2005;146:624-632.

13 Haas E, Meyer MR, Schurr U, Bhattacharya I, Minotti R, Nguyen HH, Heigl A, Lachat M, Genoni M, Barton M: Differential effects of 17beta-estradiol on function and expression of estrogen receptor alpha, estrogen receptor beta, and GPR30 in arteries and veins of patients with atherosclerosis. Hypertension 2007;49:1358-1363.

14 Bologa CG, Revankar CM, Young SM, Edwards BS, Arterburn JB, Kiselyov AS, Parker MA, Tkachenko SE, Savchuck NP, Sklar LA, Oprea TI, Prossnitz ER: Virtual and biomolecular screening converge on a selective agonist for GPR30. Nat Chem Biol 2006;2:207212.
15 Haas E, Bhattacharya I, Brailoiu E, Damjanovic M, Brailoiu GC, Gao X, MuellerGuerre L, Marjon NA, Gut A, Minotti R, Meyer MR, Amann K, Ammann E, PerezDominguez A, Genoni M, Clegg DJ, Dun NJ, Resta TC, Prossnitz ER, Barton M: Regulatory role of $\mathrm{G}$ protein-coupled estrogen receptor for vascular function and obesity. Circ Res 2009;104:288-291.

16 Lindsey SH, Cohen JA, Brosnihan KB, Gallagher PE, Chappell MC: Chronic treatment with the $\mathrm{G}$ protein-coupled receptor 30 agonist G-1 decreases blood pressure in ovariectomized mRen2.Lewis rats. Endocrinology 2009;150:3753-3758.

17 Broughton BR, Miller AA, Sobey CG: Endothelium-dependent relaxation by $\mathrm{G}$ proteincoupled receptor 30 agonists in rat carotid arteries. Am J Physiol Heart Circ Physiol 2010;298:H1055-H1061.

18 Wakeling AE, Dukes M, Bowler J: A potent specific pure antiestrogen with clinical potential. Cancer Res 1991;51:3867-3873.

19 Howell A, Osborne CK, Morris C, Wakeling AE: ICI 182,780 (Faslodex): development of a novel, 'pure' antiestrogen. Cancer 2000;89: 817-825.

20 Vergote I, Abram P: Fulvestrant, a new treatment option for advanced breast cancer: tolerability versus existing agents. Ann Oncol 2006;17:200-204.

21 Brandes RP, Barton M, Philippens KM, Schweitzer G, Mügge A: Endothelial-derived superoxide anions in pig coronary arteries: evidence from lucigenin chemiluminescence and histochemical techniques. J Physiol 1997;500:331-342. 
>22 Leung HS, Yung LM, Leung FP, Yao X, Chen ZY, Ko WH, Laher I, Huang Y: Tamoxifen dilates porcine coronary arteries: roles for nitric oxide and ouabain-sensitive mechanisms. Br J Pharmacol 2006;149:703-711.

-23 Tummala S, Hill BJ: The enhanced endothelin-1-induced contraction in cultured coronary arteries from mature female pigs is not antagonized by 17beta-estradiol. Vascul Pharmacol 2007;46:346-352.

24 Fuster V, Ip JH, Badimon L, Badimon JJ, Stein B, Chesebro JH: Importance of experimental models for the development of clinical trials on thromboatherosclerosis. Circulation 1991;83(Suppl 6):IV15-IV25.

-25 DeLean A, Munson PJ, Rodbard D: Simultaneous analysis of families of sigmoidal curves: application to bioassay, radioligand assay, and physiological dose-response curves. Am J Physiol 1978;235:E97-E102.

-26 Takada Y, Kato C, Kondo S, Korenaga R, Ando J: Cloning of cDNAs encoding G protein-coupled receptor expressed in human endothelial cells exposed to fluid shear stress. Biochem Biophys Res Commun 1997; 240:737-741.

-27 Mercier I, Mader S, Calderone A: Tamoxifen and ICI 182,780 negatively influenced cardiac cell growth via an estrogen receptorindependent mechanism. Cardiovasc Res 2003;59:883-892

-28 Ullrich ND, Krust A, Collins P, MacLeod KT: Genomic deletion of estrogen receptors ERalpha and ERbeta does not alter estrogenmediated inhibition of $\mathrm{Ca}^{2+}$ influx and contraction in murine cardiomyocytes. Am J Physiol Heart Circ Physiol 2008;294:H2421H2427.

-29 Teoh H, Leung SW, Man RY: Short-term exposure to physiological levels of 17 beta-estradiol enhances endothelium-independent relaxation in porcine coronary artery. Cardiovasc Res 1999;42:224-231.
30 Sudhir K, Chou TM, Mullen WL, Hausmann D, Collins P, Yock PG, Chatterjee K: Mechanisms of estrogen-induced vasodilation: in vivo studies in canine coronary conductance and resistance arteries. J Am Coll Cardiol 1995;26:807-814.

31 Shaw L, Taggart MJ, Austin C: Mechanisms of 17 beta-oestradiol induced vasodilatation in isolated pressurized rat small arteries. $\mathrm{Br}$ J Pharmacol 2000;129:555-565.

32 Bracamonte MP, Jayachandran M, Rud KS Miller VM: Acute effects of 17beta-estradiol on femoral veins from adult gonadally intact and ovariectomized female pigs. Am J Physiol Heart Circ Physiol 2002;283:H2389H2396.

33 Scott PA, Tremblay A, Brochu M, St-Louis J: Vasorelaxant action of 17-estradiol in rat uterine arteries: role of nitric oxide synthases and estrogen receptors. Am J Physiol Heart Circ Physiol 2007;293:H3713-H3719.

34 Bucci M, Roviezzo F, Cicala C, Pinto A, Cirino G: 17-beta-oestradiol-induced vasorelaxation in vitro is mediated by eNOS through hsp90 and akt/pkb dependent mechanism. Br J Pharmacol 2002;135:1695-1700.

35 Rubanyi GM, Freay AD, Kauser K, Sukovich D, Burton G, Lubahn DB, Couse JF, Curtis SW, Korach KS: Vascular estrogen receptors and endothelium-derived nitric oxide production in the mouse aorta. Gender difference and effect of estrogen receptor gene disruption. J Clin Invest 1997;99:2429-2437.

36 Chen Z, Yuhanna IS, Galcheva-Gargova Z, Karas RH, Mendelsohn ME, Shaul PW: Estrogen receptor alpha mediates the nongenomic activation of endothelial nitric oxide synthase by estrogen. J Clin Invest 1999;103: 401-406.

37 Luksha L, Poston L, Gustafsson JA, Hultenby $\mathrm{K}$, Kublickiene K: The oestrogen receptor beta contributes to sex related differences in endothelial function of murine small arteries via EDHF. J Physiol 2006;577:945-955.
38 Figtree GA, Webb CM, Collins P: Tamoxifen acutely relaxes coronary arteries by an endothelium-, nitric oxide-, and estrogen receptor-dependent mechanism. J Pharmacol Exp Ther 2000;295:519-523.

>39 Miller AP, Xing D, Feng W, Fintel M, Chen YF, Oparil S: Aged rats lose vasoprotective and anti-inflammatory actions of estrogen in injured arteries. Menopause 2007;14:251260

40 Deschamps AM, Murphy E: Activation of a novel estrogen receptor, GPER, is cardioprotective in male and female rats. Am J Physiol Heart Circ Physiol 2009;297:H1806-H1813.

41 Bopassa JC, Eghbali M, Toro L, Stefani E: A novel estrogen receptor GPER inhibits mitochondria permeability transition pore opening and protects the heart against ischemiareperfusion injury. Am J Physiol Heart Circ Physiol 2010;298:H16-H23.

42 Collins P, Mosca L, Geiger MJ, Grady D, Kornitzer M, Amewou-Atisso MG, Effron $\mathrm{MB}$, Dowsett SA, Barrett-Connor E, Wenger NK: Effects of the selective estrogen receptor modulator raloxifene on coronary outcomes in the Raloxifene Use for The Heart trial: results of subgroup analyses by age and other factors. Circulation 2009;119:922-930.

43 Cummings SR, Ensrud K, Delmas PD, La Croix AZ, Vukicevic S, Reid DM, Goldstein S, Sriram U, Lee A, Thompson J, Armstrong RA, Thompson DD, Powles T, Zanchetta J, Kendler D, Neven P, Eastell R: Lasofoxifene in postmenopausal women with osteoporosis. N Engl J Med 2010;362:686-696.

44 Filice E, Recchia AG, Pellegrino D, Angelone T, Maggiolini M, Cerra MC: A new membrane $\mathrm{G}$ protein-coupled receptor (GPR30) is involved in the cardiac effects of 17beta-estradiol in the male rat. J Physiol Pharmacol 2009;60:3-10. 